\title{
Ethnic Pattern of Origin of Children with Spina Bifida Managed at the University Teaching Hospital and Beit Cure Hospital, Lusaka, Zambia 2001-2010
}

\author{
Margaret M. Mweshi ${ }^{1}$, Seyi Ladele Amosun ${ }^{2}$, Mary P. Shilalukey-Ngoma ${ }^{3}$, \\ Esther Munalula-Nkandu ${ }^{1}$ \\ ${ }^{1}$ Department of Physiotherapy, School of Medicine, University of Zambia, Lusaka, Zambia \\ ${ }^{2}$ Division of Physiotherapy, School of Health \& Rehabilitation Sciences, University of Cape Town, Cape Town, South Africa \\ ${ }^{3}$ Department of Pediatric \& Child Health, School of Medicine, University of Zambia, Lusaka, Zambia
}

Email address:

srmmweshi@gmail.com (M. M. Mweshi)

\section{To cite this article:}

Margaret M. Mweshi, Seyi Ladele Amosun, Mary P. Shilalukey-Ngoma, Esther Munalula-Nkandu. Ethnic Pattern of Origin of Children with Spina Bifida Managed at the University Teaching Hospital and Beit Cure Hospital, Lusaka, Zambia 2001-2010. Science Journal of Public Health. Vol. 3, No. 6, 2015, pp. 852-856. doi: 10.11648/j.sjph.20150306.19

\begin{abstract}
The incidence of spina bifida (SB) is known to differ among regions. Very little has been reported about the relationship between the incidence of SB and ethnic patterns of origin in Zambia except for the general impression that it is prevalent. The aim of the study was to establish the ethnic pattern of origin of children with SB in Zambia. It was a retrospective cross sectional study. Using a checklist, data was collected from clinical files of children with SB from the University Teaching Hospital (UTH) and Beit Cure Hospital (BCH) from 2001-2010. Descriptive statistical analysis was done in SPSS version 17. A total of 253 children with SB were identified of whom 88 (35\%) of them originally came from the Southern Province of the country while the lowest province was the North-Western Province with 7 (3\%). Further, a total of 77 $(30 \%)$ children were referred from the Southern Province of the country and the lowest province that was represented was the North-Western Province with $5(2 \%)$. Observed is the evidence that SB is very prevalent in the Southern Province of the country. With the presence of Uranium in the Southern Province of Zambia, a serious study ought to be done to investigate the possible link of the pollutant with the prevalence of SB in the region. It is essential that the government looks seriously at Uranium Mines being operated in the Province.
\end{abstract}

Keywords: Ethnic Patterns, Spina Bifida, Management, Southern Province, Uranium Deposits

\section{Introduction}

Birth defects (BD) are common, costly and critical as they impact the quality of life of the whole family, often in negative ways. Spina Bifida (SB) is one of the BD of the Central Nervous System (CNS) and is the commonest of the Neural Tube Defects (NTDs) [1]. While considerable advancement could be made in preventing SB through folic acid supplementation, many women of childbearing age are unaware of the relationship between folic acid and neural tube defects. However, SB still affects nearly 1 in 2, 000 live births [1] although there remains a paucity of data on BD in most African countries [2]. There is a scarcity of studies on the specific incidence of SB in Zambia. Limited published data show results of a study that was done to evaluate major congenital anomalies at the UTH in 1976 which revealed that the incidence of SB was 0.57 per 1,000 births [3].

It is well established that human pregnancy and fetal development are susceptible to parents' environmental exposure to chemical, biological and physical agents $[4,5]$. Air and water pollution, exposure to toxic metals, and exposure to persistent and volatile organics have been linked to adverse pregnancy and developmental outcomes $[6,7]$. Mining regions specifically have vast areas of disturbed soils contaminated with a variety of environmental metals including arsenic, lead, nickel, uranium, vanadium, copper, and iron, as well as many others depending on the location and type of minerals being mined $[8,9]$. Reports show that the Sothern Province of Zambia is found in the Zambezi Rift Valley which is hilly with large fault bounded valleys filled with Permian, Triassic and possibly Cretaceous sediments of 
the Karoo Super group with uranium deposits [10]. Uranium deposits are reported in Mutanga, Mutanga Extension, Dibwe and Dibwe extension. The source of the uranium is believed to be the surrounding Proterozoic gneisses and plutonic basement rocks. Having been weathered from these rocks, the uranium was dissolved, transported in solution and precipitated under reducing conditions in siltstones and sandstones. Post lithification fluctuations in the groundwater table caused dissolution, mobilization and re-deposition of uranium in reducing, often clay-rich zones and along fractures [11]. The habit of eating red/ white soil during pregnancy in most Zambian women is a great source of concern especially those found in the Southern Province of the country.

Given such kind of information on the already established link between some pollutants like Uranium and SB, we set out to establish if there was an ethnic pattern of referrals and origins among the children with SB who were managed at the University Teaching Hospital and Beit Cure Hospital in Zambia between 2001 and 2010.

\section{Methodology}

A descriptive retrospective cross-sectional study design

with quantitative methods was utilized. Using a checklist, data was collected from clinical files of children with SB from the University Teaching Hospital (UTH) and Beit Cure Hospital (BCH) from 2001-2010. Both hospitals are found in Lusaka and are the only centers providing specialized care to children with SB in Zambia. The UTH is the largest referral hospital in the country that provides several services to the general public by providing specialized diagnostic and surgical procedures, and also conducts research on commonly occurring diseases in the country.

The study clearance and approval was sought from the Biomeical Research Ethics Committee of the, University of Zambia (UNZABREC). The process of data collection started by orientating the three research assistants who are physiotherapists by profession on how to extract relevant information from the clinical files and eventually entering data on the SPSS data base. Descriptive statistics was used to analyze the data using SPSS version 17. Categorical variables were compared using either the Fishers' Exact test or Chi-square test. The level of statistical significance was set at $p \leq 0.05$ at $95 \%$ Confidence Interval.

\section{Results}

\begin{tabular}{|c|c|c|c|c|c|c|c|}
\hline \multicolumn{8}{|l|}{ Coccygeal } \\
\hline \\
\hline \multicolumn{8}{|l|}{ Lumbo-Sacral } \\
\hline \multirow{2}{*}{\multicolumn{8}{|c|}{ Lumbar }} \\
\hline \multirow{2}{*}{\multicolumn{8}{|c|}{ Thoraco-Lumbar }} \\
\hline & & & & & & & \\
\hline \multicolumn{8}{|l|}{ Thoracic } \\
\hline \multicolumn{8}{|l|}{ Cervical } \\
\hline \multirow[t]{2}{*}{0} & & 0.2 & 0.4 & 0.6 & 0.8 & 1 & 1.2 \\
\hline & Cervical & Thoracic & $\begin{array}{l}\text { Thoraco- } \\
\text { Lumbar }\end{array}$ & Lumbar & Lumbo-Sacral & Sacral & Coccygeal \\
\hline Myelomeningocele & $33 \%$ & $57 \%$ & $89 \%$ & $65 \%$ & $76 \%$ & $100 \%$ & $33 \%$ \\
\hline Meningocele & $67 \%$ & $43 \%$ & $11 \%$ & $33 \%$ & $22 \%$ & $0 \%$ & $67 \%$ \\
\hline -Lypomenigocele & 0 & 0 & 0 & $2 \%$ & $2 \%$ & 0 & 0 \\
\hline
\end{tabular}

Figure 1. Type of spina bifida by location.

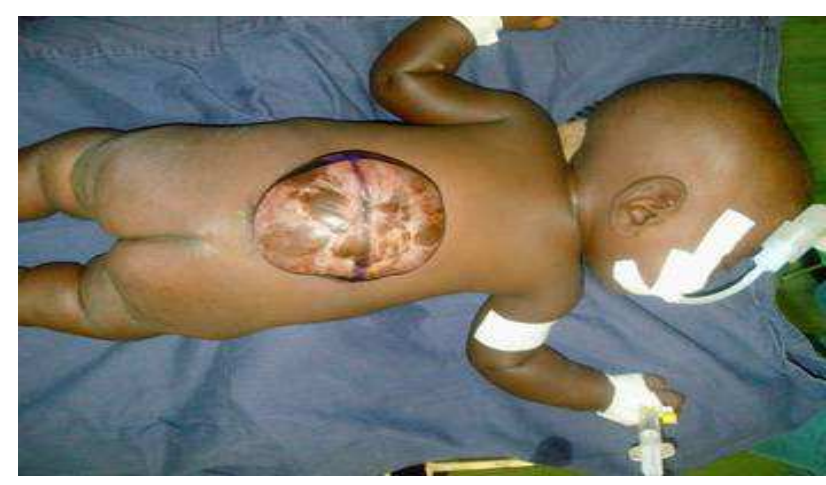

Figure 2. Child with myelomeningocele before surgery.

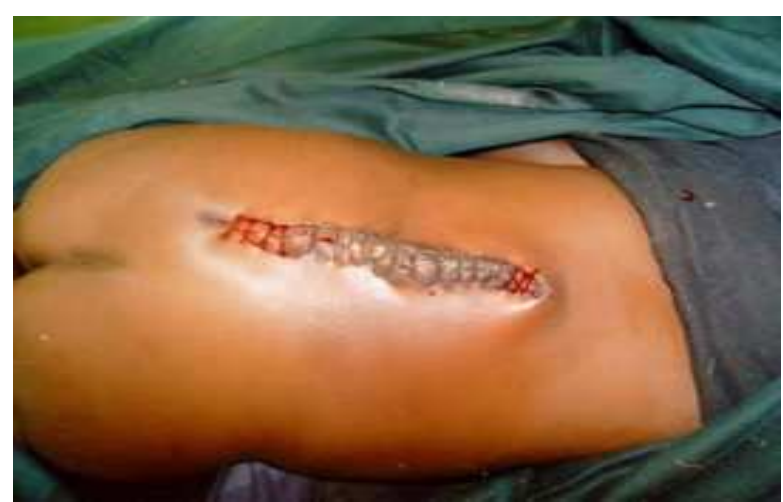

Figure 3. Same child after surgery. 
A total of 253 children with SB were identified during the period under review. Results showed that there were 139 (55\%) males and $114(45 \%)$ females $(p=0.116)$ among the children with SB. The results of the study (figure 1) showed that 154 patients $(61 \%$; $\mathrm{p}<0.001)$ had myelomeningocele, $79(31 \%)$ meningocele and $4(2 \%)$ lipomeningoceles. Results with regards the site of the defect, the lumbar region had 159 (63\%; $\mathrm{p}<0.001)$, lumbo-sacral $41(16 \%)$, thoracolumbar 19 (7\%), sacral $3(1 \%)$, cervical $12(5 \%)$, thoracic $7(3 \%)$ and lastly, coccygeal $12(5 \%)$. Figures 2 and 3 shows a baby with $\mathrm{SB}$ with a giant lumbo-thoracic sac before and after surgery.

Further, it was noted (figure 4) that $88(35 \%$; p $<0.001)$ children originally came from the Southern Province of the country, followed by Lusaka Province with 58 (23\%) and the lowest province represented was the North-Western Province with $7(3 \%)$. The pattern of province of origin was the same with regard to province of referral where $77(30 \% ; p<0.001)$ children were referred from the Southern Province of the country followed by Lusaka Province with 74 (24\%) and the lowest province that was represented was the North-Western Province with 5 (2\%). However the Central Province (18\%) of the country referred also a substantial number of children for management.

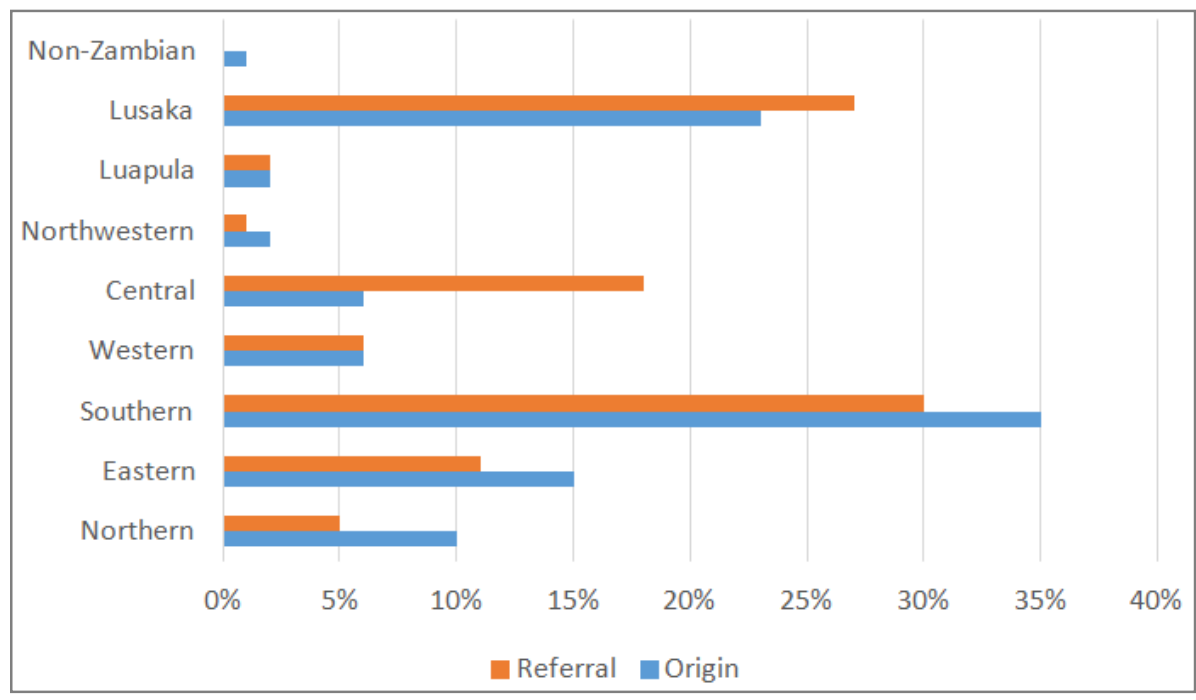

Figure 4. Province of Referrals of children with spina bifida by Province of Origin.

\section{Discussion}

The results of this current study showed there were more boys with SB than girls. It has been observed that gender differences clearly exist in the prevalence of SB. It is essential to note in literature that at birth, SB tends to be more common in girls than in boys at a sex ratio of $1 / 0.8$ obtained for instance from a study that showed that $70 \%$ of the neonates were girls while $30 \%$ were boys $[12,13]$. Other studies are also consistent with such findings that females are more likely to have SB than males and this predominance appears to be influenced by the presence of additional birth defects, geographical areas and other factors [14]. Potential explanations given for the predominance among females include differences between the sexes in embryonic developments' susceptibility to teratogenic insult and spontaneous abortion rates $[15,16]$. However, amidst such evidence, it is important to note that the results of the current study present contrasting views of male predominance in the management. With such distinct evidence, it is essential to highlight that some sub-Saharan African countries like Nigeria and Cameroon have presented results showing male predominance during the management, $[15,17]$ hence the results are in line with such findings. Probably an explanation can be connected to ethno-theories where boys are much more treasured than girls in most societies in sub-Saharan Africa.
It has been reported globally that myelomeningocele is the most common defect in SB $[15,18,19]$. This postulation has been supported by the results of a prospective study done in a large Cosmopolitan Western African city, which showed that the most common defect in the children with NTDs was myelomeningocele [20] although in contrast, another study was done on SB cystic in Zaria, Nigeria that showed more children with meningocele compared with myelomeningocele [21]. The present findings showed that myelomeningocele was the most common diagnosis in the treatment cohort hence supporting the reports attesting that myelomingocele is the commonest defect.

There seem to be contrasting views on the common site of the defect in SB. For instance Champbell and others [19] report that approximately $80 \%$ of all lesions in infants with SB occur in the lumbar region and others also have subscribed to the same concept and went on to justify that the lumbar region is the last region of the neural tube to close [22]. Conversely, some studies have found that the lumbosacral region is the commonest site for SB [21, 23, 24] while a study done in Zambia showed the sacral region to be the most common site of occurrence [25]. However, the current results support the notion that the lumbar region is significantly, the common site being affected although dissimilar with other findings.

The results showed that the majority of patients were 
originally from the Southern Province of the country. In the quest to understand some of the likely causes of SB in order to create preventive measures, one of the issues that need to be further investigated is the rock stratum and geological faults in the Southern part of the country. This could probably explain why some uranium mines have been abandoned in the USA [26]. However, these mine wastes represent mixtures of metals including not only uranium, but also arsenic, copper, and other heavy metals, as well as remaining radionuclides. There is evidence that quinoline and trichloroethylene may be significant contributors to the risk of SB [27]. This can be confirmed by the results of a study that was done in China and showed that the age of rock stratum has a positive correlation with the occurrence ratio of NTDs [28]. Furthermore, it has been noted that the older the base rock, the higher concentration of Radon in soil, water and air.

Even though such information has been availed, no systematic investigation has been undertaken to understand how exposures in the numerous rural tribal communities in proximity to these wastes might affect health, especially in children in the USA [26]. But most importantly, some questions still remain unanswered like; could environmental contaminants interact with genetic factors to trigger the development of SB? And if so, how can we further our understanding of relationships between exposure and SB?

There has been some public concern over the Uranium mines in the Southern Province of Zambia. For instance one article in the Post News Paper of the $5^{\text {th }}$ September 2010 highlighted why there is no policy to safeguard the interests of the Zambian people. With the current weak and inadequate ionizing radiation legal and policy framework, the country may continue mining uranium at the detriment of its own people and the safety of the environment. There is a great likelihood that some Canadian Miners may continue to pursue the expansions of such mines when the USA has reported abandoning its' Uranium Mines because of the harm it has which cannot be disputed. It is therefore amenable that future studies are done in order to assess and analyze the possible causes of human birth defect in this region of Zambia before these mines expand further.

\section{Conclusion}

Observed is the evidence that SB is very prevalent in the Southern Province of the country. It has been noted that myelomeningocele is the most common type of SB prevalent in the country and the lumbar region is the most affected region.

\section{Recommendations}

It is highly recommended that an extensive study to be executed in the areas of Matanga and Dibwe in Southern Province of the country to investigate the predominance of $\mathrm{SB}$. It is also recommended that adequate ionizing radiation legal and policy framework put in place.

\section{Acknowledgements}

The research report presented arose from the research project data base that was part of the academic requirements for the Doctor of Philosophy Degree in Physiotherapy at the University of Zambia. We wish to sincerely thank the managements of the University Teaching Hospital and Beit Cure Hospital for their support during the time of the study.

\section{References}

[1] Adzick NS (2010). Foetal myelomeningocele: Natural history, pathophysiology and in-utero intervention. Seminars in Foetal \& Neonatal Medicine, 15, 9-14.

[2] Kashimba Rogath Saika, Mpembeni Rose, Mghamba M Janneth, David Goodman, Diana Valencia (2015). Birth prevalence of selected external structural birth defects at four hospitals in Dar es Salaam, Tanzania, 2011-2012. Journal of Global Health, 5: 2 (1-6).

[3] Sukhani S, Patel YK, Chintu C (1977). Major congenital malformations in neonates at U.T.H. Lusaka Zambia. Med $J$ Zambia, 11(5): 127-38.

[4] Mattison RD (2010). Environmental Exposures and Development. Curr Opin Pediatr. 22(2): 208-218.

[5] Al-Sabbak MS, Sadik AO, Savabi G, Savabi S, Dastgiri M. Savabieasfahani (2012). Metal Contamination and the Epidemic of Congenital Birth Defects in Iraqi Cities. Bull Environ Contam Toxicol 89: 937-944.

[6] Landrigan P, Kimmel C, Correa A, Eskenazi B et al (2004). Children's health and the environment: public health issues and challenges for risk assessment. Environ Health Perspect 112(2): 257-265.

[7] Bocskay K, Tang D, Orjuela M, Liu X, Warburton D, Perera F et al (2005). Chromosomal aberrations in cord blood are associated with prenatal exposure to carcinogenic polycyclic aromatic hydrocarbons. Cancer Epidemiol Biomarkers Prev 14(2): 506-511.

[8] Ahern M, Hendryx M, Conley J, Fedorko E, Ducatman A, Zullig K et al (2011). The association between mountaintop mining and birth defects among live births in central Appalachia, 1996-2003. Environ Res 111(6): 838-846.

[9] Wu J, Zhang C Pei L, Chen G, \& Zheng X (2014). Association between risk of birth defects occurring level and arsenic concentrations in soils of Lvliang, Shanxi province of China. Environ Pollut. 191: 1-7.

[10] Technical Report, Republic of Zambia (2012). The Dibwe East Project, Southern Province, Republic of Zambia. National Instrument 43-101 Technical Report.

[11] Lusambo V (2011). Local Geology of Dibwe East Prospect (Dibwe Mutanga Corridor). Internal report for Denison Mines Zambia Limited.

[12] Mitchell LE, Adzick NS, Melchionne J, Pasquariello PS, Sutton LN and Whitehead AS (2004). Spina bifida. Lancet, 364, 1885-1895.

[13] Buccimazza SS, Molteno CD, Dunne TT, et al. (1994). Prevalence of neural tube defects in Cape Town. Teratology 50: 194-199. 
[14] Hendricks T, Francis N, Fyodorov D, Deneris ES (1999). The ETS domain factor Pet-1 is an early and precise marker of central serotonin neurons and interacts with a conserved element in serotonergic genes. J. Neurosci 19: 10348-10356.

[15] Djientcheu VP, Njamnshib AK, Wonkamc A, Njikid J, Guemsed M, Mbuf R, Obamae, AT, Kagod I, Tetayeh E and Tietched F (2008). Management of neural tube defects in a Sub-Saharan African country: The situation in Yaounde, Cameroon. Journal of Nursing Science, 275 (1), 29-32.

[16] Oduro H (2008). Enrichment of foods with folate: its impact on the prevalence of genetic associated diseases in African countries as compared to western countries. (http://departments.agri.huji.ac.il/external).

[17] Margaron FC, Poenaru D, Bransford R and Albright LA (2010). Timing of ventriculoperitoneal Shunt insertion following spina bifida closure in Kenya. Child's Nervous System, 26, (11), 1523-1528.

[18] Mehdizadeh M, Roohi A, Hemami M and Esfahani S (2010). Is There any Association between Spina Bifida Occulta and Primary Vesicoureteral Reflux? Iran Journal of Pediatric, 20 (3), 348-352.

[19] Champbell KS, Vander L and Palisano R (2006). Physical Therapy for Children. W.B. Saunders Company: Philadelphia.

[20] Airede KI (1992). Neural tube defects in the middle belt of Nigeria. Journal of Tropical Pediatrics, 38, 27-30.

[21] Shehu BB, Ameh EA and Ismail NJ (2000). Spina bifida cystic: selective management in Zaria, Nigeria. Annals of Tropical Paediatrics 20 (3), 239-42.
[22] Volpe J (2001). Neural tube formation and prosencephalic development. In: Volpe J(ed) Neurology of the new born. WB Sanders: Philadelphia.

[23] Idowu OE and Apemiye RA (2008). Outcome of myelomeningocele repair in sub-Saharan Africa: the Nigerian experience. Acta Neurochir (Wien), 159, 911-913.

[24] Botto LD, Moore CA, Khoury MJ and Erickson JD (1999). Neural-tube defects. New England Journal of Medicine, 341, $1509-1519$.

[25] Lungu MM (2001). Epidemiological characteristics of patients with myelomeningocele presenting to University Teaching Hospital - Lusaka. Master's Degree Thesis, University of Zambia.

[26] Anyanwu Lofty-John Chukwuemeka, Danborno Barnabas, Hamman Wilson Oliver (2015). The Prevalence of Neural Tube Defects in Live Born Neonates in Kano, North-western Nigeria. Sub-Saharan African Journal of Medicine /Vol 2/Issue 3: 105-109.

[27] Swartz D Michael, Yi Cai1, Wenyaw Chan, Elaine Symanski, Laura E Mitchell, Heather E Danysh, Peter H Langlois and Philip J Lupo (2015). Air toxics and birth defects: a Bayesian hierarchical approach to evaluate multiple pollutants and spina bifida. Environmental Health, 14:16.

[28] Li Z, Ren A, Zhang L, Ye R, Li S, Zheng J, Hong S, Wang T and Li L (2006). Extremely high prevalence of neural tube defects in a 4-county area in Shanxi Province, China. Birth defects research. Part A. Clinical and Molecular Teratology, 74(4), 237-40. 